\title{
Preexposure Prophylaxis (PrEP) for HIV Prevention: The Primary Care Perspective
}

James Conniff, $M D$, and Ann Evensen, $M D$

Until recently there have been few primary care office-based strategies to reduce the transmission of HIV. In May 2014 the Centers for Disease Control and Prevention published updated practice guidelines recommending the use of preexposure prophylaxis (PrEP) with daily oral dosing of tenofovir/ emtricitabine to help prevent HIV infection in high-risk individuals (strength of recommendation, A). Knowledge of PrEP among primary care providers is low, however, and this intervention is likely reaching only a small fraction of eligible patients. PrEP is recommended for certain injection drug users, nonmonogamous men who have sex with men, heterosexual women who have sex with men who have sex with men or injection drug users, and those in HIV serodiscordant relationships. Providers should obtain baseline laboratory values and provide initial counseling before prescribing PrEP. Regular office visits are necessary to ensure adherence, provide ongoing counseling, and monitor for side effects, including nausea, abdominal pain, headache, and, less commonly, increased creatinine. Guidelines and toolkits have been developed to assist in incorporating PrEP into primary care practice. PrEP is gaining widespread acceptance and has become a crucial tool in the fight to stop the spread of HIV. (J Am Board Fam Med 2016;29:143-151.)

Keywords: Communicable Diseases, HIV, Infectious Diseases, Pharmacotherapy, Prevention \& Control, Primary Health Care

More than 1.2 million Americans were living with $\mathrm{HIV}$ in 2013. Of those, $15 \%(\mathrm{n}=168,300)$ were not aware of their infection. There also were 47,000 new infections (15.0 per 100,000). This overall incidence masks a wide range of rates, from 1.8 per 100,000 among white women to 105.7 per 100,000 among African American men. Over 60\% of new infections occurred among men who have sex with men (MSM). ${ }^{1}$

Most HIV prevention strategies, such as condom distribution and HIV testing and counseling campaigns, have been implemented on a popula-

This article was externally peer reviewed.

Submitted 18 July 2015; revised 15 September 2015; accepted 25 September 2015.

From the Department of Family Medicine and Community Health, University of Wisconsin-Madison, Madison.

Funding: The work was funded by a Health Resources and Services Administration Ruth T. Kirschstein training grant (grant no. T32 HP10010-23-00 to JC).

Conflict of interest: none declared.

Corresponding author: James Conniff, MD, Department of Family Medicine and Community Health, University of Wisconsin-Madison, 1339 E. Wilson St, Madison, WI 53703 (E-mail: james.conniff@fammed.wisc.edu). tion level. ${ }^{2}$ By contrast, 4 office-based approaches to HIV prevention are currently available to primary care clinicians. The US Preventive Services Task Force recommends high-intensity behavioral counseling on sexual risk reduction for sexually transmitted infections (STIs) (grade B), but the time and resources required for such intensive counseling may be prohibitive for many providers and patients. ${ }^{3}$ Treatment-as-prevention with combination antiretroviral therapy prevents HIV transmission by lowering community viral loads; this method has only an indirect effect on seronegative individuals. ${ }^{4}$ Male circumcision significantly reduces the risk of contracting HIV, but it has not been evaluated in low-prevalence settings and may not be acceptable to some uncircumcised men. ${ }^{5}$

The fourth and potentially most feasible strategy for clinicians and high-risk, HIV-negative patients is preexposure prophylaxis ( $\mathrm{PrEP}$ - - the use of daily antiretroviral medication to reduce the risk of acquiring HIV infection. In May 2014 the Centers for Disease Control and Prevention (CDC) published updated practice guidelines recommending 
the use of PrEP with daily oral dosing of tenofovir disoproxil fumarate (TDF)/emtricitabine (FTC) (Truvada; Gilead Sciences, Foster City, CA) for this indication. ${ }^{6}$ This recommendation is based on several randomized controlled trials $(\mathrm{RCTs})^{7-11}$ and a Cochrane review ${ }^{12}$ supporting the safety and efficacy of PrEP for high-risk individuals, including MSM, injection drug users (IDUs), and heterosexual women who have sex with MSM or IDUs. The Vancouver Consensus, which emerged from the 2015 International AIDS Society Conference, states that PrEP "must be made available to protect those at high risk of acquiring HIV."13

Despite the evidence, it is likely that this intervention is reaching only a small fraction of eligible individuals. One 2014 study of physicians in Massachusetts showed that although $99 \%$ of infectious disease specialists and $83 \%$ of generalists had heard of PrEP, only $40 \%$ of each group thought that PrEP should be readily available to all at-risk persons. ${ }^{14}$ Another 2014 study of American infectious disease specialists showed that only $9 \%$ had prescribed PrEP. ${ }^{15}$

Patients who might benefit from PrEP are likely not presenting to infectious disease physicians. Despite low awareness, primary care providers are already writing more prescriptions for PrEP than are specialists. ${ }^{16}$ If more family physicians and other primary care providers feel comfortable prescribing PrEP, this strategy for reducing HIV prevalence may reach more individuals who are vulnerable to infection. ${ }^{17}$ This article reviews the use of PrEP as an HIV prevention strategy that complements other established strategies to reduce HIV risk, and helps primary care clinicians understand how to most effectively prescribe TDF/FTC.

\section{Evidence Base}

A number of RCTs have established the efficacy of PrEP with TDF/FTC or TDF alone to prevent HIV transmission among high-risk populations. PrEP has significantly reduced HIV transmission rates among sexually active men and women in Botswana, a country with a high HIV burden'; among serodiscordant heterosexual couples in eastern Africa ${ }^{8}$; among IDUs in Thailand ${ }^{10}$; and among a global sample of MSM that included participants in San Francisco and Boston. ${ }^{7}$ A Cochrane metaanalysis of these studies found a relative risk of acquiring HIV infection of 0.49 (95\% confidence interval, $0.28-0.85$ ) for those taking TDF/FTC daily and 0.33 (95\% confidence interval, $0.20-$ 0.55 ) for those taking TDF alone. There was no statistically significant difference in HIV incidence between groups using TDF/FTC compared with TDF alone, and neither group had a significantly increased risk of adverse events. ${ }^{12}$ Early results from subsequent open-label studies suggest that PrEP is effective ${ }^{18}$ and adherence is high ${ }^{19}$ in realworld as well as investigational settings.

The benefits of PrEP for female patients who do not use intravenous drugs are less clear. Three randomized controlled trials conducted in Africa failed to show any statistically significant reduction in HIV incidence among heterosexual women using daily oral PrEP. ${ }^{20-22}$ Two studies also investigated the use of pre- and postcoital tenofovir vaginal gel, but only one of these found a statistically significant effect on HIV incidence. $^{22,23}$ While nonadherence likely contributed to the lack of effect, the authors of one study noted that some HIV infections occurred in female study participants with detectable serum concentrations of tenofovir. ${ }^{21}$

Trials published to date have investigated only the daily use of TDF or TDF/FTC among adults. Early results show that PrEP may also be effective as a "bridge" to antiretroviral therapy in serodiscordant African couples. ${ }^{24}$ RCTs are currently underway to investigate the use of PrEP with TDF/FTC in adolescents, ${ }^{25-28}$ intermittent "on-demand" dosing with TDF/FTC in adults, ${ }^{29,30}$ and an injectable depot formulation in adults that would only require treatment once every 3 months. ${ }^{31,32}$ Early results from one trial of "on-demand" PrEP for MSM are encouraging. ${ }^{33}$

\section{Indications for Use}

The CDC recommends the use of daily TDF/ FTC in selected patients who are at high risk of acquiring HIV through sexual contact and/or intravenous injection of drugs not prescribed for them. ${ }^{6}$ Candidates should be adults known to be HIV negative immediately before starting PrEP. TDF/FTC for PrEP is approved by the US Food and Drug Administration only for adults who are not breastfeeding and have a creatinine clearance $>60 \mathrm{~mL} / \mathrm{min}$. ${ }^{6,34} \mathrm{TDF} / \mathrm{FTC}$ is probably safe during pregnancy (US Food and Drug Administration pregnancy category B), but because of a small number of observed fetal exposures, fetal 
Table 1. Indications for the Use of Preexposure Prophylaxis Among Adult Patients with No Acute or Established HIV Infection

\begin{tabular}{|c|c|}
\hline $\begin{array}{l}\text { MSM and } \\
\text { transgender } \\
\text { females }\end{array}$ & $\begin{array}{l}\text { Any male sex partner in the past } 6 \text { months } \\
\text { AND } \\
\text { not in a monogamous relationship with a } \\
\text { recently tested HIV-negative partner AND } \\
\text { one of the following: } \\
\text { - any anal sex without condoms (receptive or } \\
\text { insertive) in the past } 6 \text { months OR } \\
\text { - any STI reported or diagnosed in the past } \\
6 \text { months OR } \\
\text { - is in an ongoing relationship with an HIV- } \\
\text { positive man }\end{array}$ \\
\hline $\begin{array}{l}\text { Patients who } \\
\text { inject drugs }\end{array}$ & $\begin{array}{l}\text { Any injection of drugs (not prescribed) in the } \\
\text { past } 6 \text { months AND } \\
\text { one of the following: } \\
\text { - any sharing of drug injection or } \\
\text { preparation equipment in the past } 6 \\
\text { months OR } \\
\text { - treated in a methadone, buprenorphine, or } \\
\text { suboxone program in the past } 6 \text { months } \\
\text { OR } \\
\text { - meets sexual risk criteria described above } \\
\text { or below }\end{array}$ \\
\hline $\begin{array}{l}\text { Heterosexual } \\
\text { men and } \\
\text { women }\end{array}$ & $\begin{array}{l}\text { Any sex with opposite-sex partners in the } \\
\text { past } 6 \text { months AND } \\
\text { not in a monogamous relationship with a } \\
\text { recently tested HIV-negative partner AND } \\
\text { one of the following: } \\
\text { - is a man who has sex with both men and } \\
\text { women* OR } \\
\text { - uses condoms infrequently with a partner } \\
\text { known to be bisexual or use IV drugs OR } \\
\text { - is in an ongoing relationship with an HIV- } \\
\text { positive partner }\end{array}$ \\
\hline
\end{tabular}

From ref. 6.

*That is, who is behaviorally bisexual; please also see the criteria for men who have sex with men (MSM).

IV, intravenous; STI, sexually transmitted infection.

outcomes among pregnant women should be monitored using the Antiretroviral Pregnancy Registry (www.apregistry.com/). Specific selection criteria are listed in Table 1.

Because the risks of long-term use of TDF/FTC for PrEP are not fully known (see "Individual-
Level Risks," below), some clinicians use a timelimited prevention strategy to refine the use of PrEP for appropriate candidates. These clinicians consider prescribing PrEP for use in high-risk time periods, such as when previously safe relationships are disrupted, at one's sexual debut and during struggles with sexual orientation, or when a seronegative male is attempting to conceive with a seropositive female partner. ${ }^{35,36}$ Resources exist for helping clinicians choose appropriate candidates, including the PrEPline, a PrEP support hotline (1-855-448-7737, or 1-855-HIV-PREP) for clinicians that is operated by the Clinical Consultation Center at the University of California, San Francisco.

\section{Initial Evaluation and Ongoing Monitoring}

After behavioral screening identifies a patient as a potential candidate for PrEP, laboratory testing is necessary before the medication can be prescribed (Table 2). It is of critical importance that patients using PrEP be HIV negative. TDF/FTC alone is not adequate for HIV treatment; the use of PrEP in patients who are already infected with HIV may select for resistant HIV strains. Since it is difficult to clinically distinguish acute HIV from other acute viral syndromes, treatment should be deferred and testing for HIV RNA should be considered if fever, myalgias, arthralgias, or new lymphadenopathy is present. $^{6}$

If all indicated testing is negative, PrEP should ideally be started 7 to 21 days before intercourse or other high-risk behaviors. ${ }^{35}$ Once a patient is taking PrEP, CDC guidelines recommend reevaluation in the clinic every 90 days to test for HIV (to prevent inadvertent use in HIV infection); to reinforce risk reduction behaviors; and to assess for medication side effects, STIs (including hepatitis B), pregnancy, and pregnancy intent (Tables 2 and

Table 2. Laboratory Evaluation and Monitoring for Use of Preexposure Prophylaxis

\begin{tabular}{llc}
\hline What to Assess & \multicolumn{1}{c}{ How to Assess } & When to Assess \\
\hline HIV serostatus & $\begin{array}{c}\text { Antibody (serum or point-of-care) or nucleic } \\
\text { acid testing }\end{array}$ & $\begin{array}{c}\text { No more than } 7 \text { days before starting PrEP and every } 3 \text { months } \\
\text { thereafter }\end{array}$ \\
HBV serostatus & HBsAb, HBsAg, HBcAb & $\begin{array}{c}\text { Before starting PrEP, }{ }^{6} \text { and can be considered thereafter, } \\
\text { depending on behavioral risks or potential exposures }\end{array}$ \\
Renal function & Creatinine clearance & $\begin{array}{c}\text { Befo starting PrEP, at 3 months, and every 3-6 months } \\
\text { thereafter, depending on baseline function }\end{array}$ \\
Pregnancy & Qualitative pregnancy test & Before starting PrEP and every 3 months thereafter
\end{tabular}

$\mathrm{HBV}$, hepatitis B virus; PrEP, preexposure prophylaxis. 
Table 3. Patient Assessments and Counseling Topics for Use of Preexposure Prophylaxis

\begin{tabular}{|c|c|}
\hline Screening/Counseling & Rationale \\
\hline Behavioral risk reduction & $\begin{array}{l}\text { Effective use of PrEP depends on synergy with motivational interviewing or multifaceted } \\
\text { interventions to reduce high-risk sexual practices and/or injection drug use. }{ }^{38}\end{array}$ \\
\hline STI screening & $\begin{array}{l}\text { Activities that increase risk for HIV also increase risk for other STIs, and screening for } \\
\text { STI symptoms may be appropriate. }\end{array}$ \\
\hline Pregnancy intent and contraception & $\begin{array}{l}\text { While PrEP is FDA approved for use during pregnancy and is potentially a valuable tool } \\
\text { in preventing transmission during that time, the safety of PrEP for the developing } \\
\text { fetus is not well studied; this should be discussed with any patient hoping to } \\
\text { conceive. }\end{array}$ \\
\hline $\begin{array}{l}\text { Alcohol and drug abuse (including } \\
\text { inhaled stimulants and amyl } \\
\text { nitrate) }\end{array}$ & $\begin{array}{l}\text { These may increase risk of renal and hepatic side effects and decrease adherence to the } \\
\text { PrEP regimen. }\end{array}$ \\
\hline Use of renally cleared medications & $\begin{array}{l}\text { TDF/FTC is renally cleared, and drug concentrations will be higher when used with } \\
\text { other renally cleared medications, including acyclovir and other antiretrovirals. }{ }^{39}\end{array}$ \\
\hline $\begin{array}{l}\text { Risk for bone loss (including possible } \\
\text { measurement of bone density) }\end{array}$ & Bone loss without fracture was noted in some studies. ${ }^{7,9}$ \\
\hline
\end{tabular}

FDA, US Food and Drug Administration; PrEP, preexposure prophylaxis; STI, sexually transmitted infection; TDF/FTC, tenofovir/ emtricitabine.

3). New York State guidelines are more conservative and recommend follow-up 30 days after initiating PrEP to assess for adherence, tolerance, and commitment to continuing PrEP. ${ }^{40}$ PrEP should be prescribed for $\leq 90$ days to ensure adherence to screening and counseling recommendations. ${ }^{6}$ No study has investigated the question of when to stop PrEP, but a conservative approach that emphasizes the adoption of alternative means of protection before discontinuing PrEP is reasonable. ${ }^{35}$

\section{Supporting Adherence to PrEP}

Since adherence to a daily regimen of TDF/FTC is clearly associated with a reduced risk of HIV seroconversion, clinicians should consider using motivational interviewing and other techniques shown to improve adherence to $\operatorname{PrEP} .^{7,23,38}$ An evaluation of interventions to promote adherence to PrEP recommended participant-centered approaches, including addressing the specific context in which an individual incorporates and negotiates PrEP use. ${ }^{41}$ While complex, resource-intensive interventions are most effective for improving adherence to medical interventions in general, a systematic review also found evidence to support low-cost, low-intensity interventions that provided education or telephone calls. ${ }^{38}$ CDC guidelines recommend that clinicians incorporate motivational interviewing into their visits for prescribing PrEP with 4 simple items: (1) When you have taken medications previously? (2) How did you remember to take them? (3) Please tell me about any problems you had taking your pills. (4) What was most helpful in remembering to take them? ${ }^{6}$

\section{Individual-Level Risks}

In studies of PrEP, TDF/FTC caused side effects in a minority of patients. In some patients these symptoms were most acute in the first 1 to 2 months of use (called "start up syndrome") and abated after longer use. ${ }^{8,9,39}$ When TDF/FTC was studied as part of a multidrug HIV treatment regimen, side effects were more severe (Table 4). The patient populations receiving PrEP and HIV treatment may vary in their baseline health and risk for complications.

$\begin{array}{ll}\begin{array}{l}\text { Table 4. Side Effects of } \\ \text { Tenofovir/Emtricitabine }\end{array} & \\ \text { T-11,21,22,39,42-45 } & \text { - Abdominal pain } \\ \text { When studied as PrEP } & \text { Nausea } \\ & \text { - Weight loss } \\ & \text { - Headache } \\ & \text { - Dizziness } \\ & \text { - Back pain } \\ & \text { Bone loss without associated } \\ & \text { fracture risk } \\ & \text { Elevated creatinine } \\ & \text { - Lactic acidosis } \\ \text { - Severe hepatomegaly with } & \text { steatosis } \\ \text { - Phen studied as part of } & \text { hepatitis B } \\ \text { a multidrug HIV } & \text { New or worsening renal failure } \\ \text { treatment regimen } & \text { Decreased serum phosphorus } \\ & \text { Bone loss without associated } \\ & \text { fracture risk }\end{array}$

PrEP, preexposure prophylaxis. 
Some have expressed concern that use of PrEP may increase high-risk sexual behaviors, ${ }^{46}$ but studies in investigational and real-world settings have not found this correlation; in two RCTs the opposite was found. 7,19 This finding may reflect the services (eg, counseling, testing, and dispensing of condoms) that are provided along with the PrEP prescription and/or the possibility that taking a daily pill is a regular reminder of imminent risk and promotes safer sex practices. ${ }^{7}$

The cost of Truvada is estimated at $\$ 800$ to $\$ 1000$ per month, with additional costs related to clinic visits and HIV, STI, and pregnancy testing. ${ }^{39,47}$ Insurance coverage varies, though websites dedicated to tracking the issue note that there has not yet been a reported case of an insurer denying coverage, including Medicare and Medicaid. ${ }^{48} \mathrm{~Pa}$ tient assistance programs have been developed to assist those without insurance coverage (Table 5).

\section{Preparing the Primary Care Office}

Armed with the information above, a busy clinician can begin prescribing PrEP to eligible patients. But improving patient access to PrEP also includes increasing patients' and nonclinical staff's awareness of this service. Advertising and educational materials in the waiting room or examination rooms may increase patient awareness. New York City's Department of Health and Mental Hygiene uses an "academic detailing" program to increase awareness among clinicians and patients about the availability of PrEP, and to help clinics prepare themselves to offer PrEP services. ${ }^{49}$ This includes a checklist for clinic readiness that recommends identifying a clinic PrEP champion; preparing clinical and reception staff; understanding billing codes and PrEP patient assistance programs; and updating clinic procedures to include appropriate patient education materials, condoms, and protocols for routine follow-up tests. ${ }^{50}$ Once the clinic and staff are prepared, many additional resources are available to help prescribers safely provide PrEP (Table 6).

\section{Systems-Level Risks and Benefits}

The decision to use PrEP has ethical implications. ${ }^{51}$ The use of PrEP to prevent HIV seroconversion benefits not only the individual but also potentially his or her close contacts and wider community, including others participating in high-risk behaviors, insurers, and health care systems. Several cost-benefit analyses have been done to explore these issues. ${ }^{47,52}$ One study of a high-risk population of MSM found that use of PrEP compared

Table 5. Patient Assistance Programs for Those without Insurance Coverage or with Other Barriers to Access to Preexposure Prophylaxis

\begin{tabular}{|c|c|c|c|}
\hline Name & Organization & Description & URL \\
\hline $\begin{array}{l}\text { Gilead U.S. Advancing } \\
\text { Access Program }\end{array}$ & Gilead Sciences, Inc. & $\begin{array}{l}\text { Manufacturer's patient } \\
\text { assistance program for } \\
\text { those with no or } \\
\text { incomplete insurance } \\
\text { coverage }\end{array}$ & http://www.truvada.com/truvada-patient-assistance \\
\hline PrEP DAP & $\begin{array}{l}\text { Washington State } \\
\text { Department of } \\
\text { Health }\end{array}$ & $\begin{array}{l}\text { Drug assistance program } \\
\text { for Washington state } \\
\text { residents who are } \\
\text { eligible for PrEP }\end{array}$ & $\begin{array}{l}\text { http://www.doh.wa.gov/YouandYourFamily/ } \\
\text { IllnessandDisease/HIVAIDS/HIVCareClient } \\
\text { Services/PrEPDAP }\end{array}$ \\
\hline $\begin{array}{l}\text { NYC Patient Assistance } \\
\text { Program }\end{array}$ & $\begin{array}{l}\text { New York City } \\
\text { Department of } \\
\text { Health and } \\
\text { Mental Hygiene }\end{array}$ & $\begin{array}{l}\text { Patient assistance } \\
\text { program to help } \\
\text { uninsured patients in } \\
\text { New York City pay } \\
\text { for PrEP }\end{array}$ & $\begin{array}{l}\text { http://www.nyc.gov/html/doh/html/living/prep- } \\
\text { pep-resources.shtml }\end{array}$ \\
\hline $\begin{array}{l}\text { Fact sheet: Pharmaceutical } \\
\text { Company Patient } \\
\text { Assistance Programs } \\
\text { and Co-Payment } \\
\text { Assistance Programs for } \\
\text { Pre-exposure } \\
\text { Prophylaxis (PrEP) and } \\
\text { Post-exposure } \\
\text { Prophylaxis (PEP) }\end{array}$ & $\begin{array}{l}\text { National Alliance of } \\
\text { State and } \\
\text { Territorial AIDS } \\
\text { Directors }\end{array}$ & $\begin{array}{l}\text { List of pharmaceutical } \\
\text { company patient } \\
\text { assistance programs }\end{array}$ & $\begin{array}{l}\text { https://www.nastad.org/sites/default/files/PrEP- } \\
\text { and-PEP-PAP-fact-sheet.pdf }\end{array}$ \\
\hline
\end{tabular}

PrEP, preexposure prophylaxis; DAP, drug assistance program. 
Table 6. Resources for Prescribing Preexposure Prophylaxis in a Clinic Setting

\begin{tabular}{|c|c|c|c|}
\hline Resource & Organization & Description & URL \\
\hline $\begin{array}{l}\text { Preexposure } \\
\text { prophylaxis for the } \\
\text { prevention of HIV } \\
\text { infection-2014: } \\
\text { clinical providers' } \\
\text { supplement }\end{array}$ & $\begin{array}{l}\text { Centers for Disease Control } \\
\text { and Prevention }\end{array}$ & $\begin{array}{l}\text { Patient and provider } \\
\text { information sheets } \\
\text { related to PrEP, HIV } \\
\text { risk index for MSM, } \\
\text { coding information, } \\
\text { and practice quality } \\
\text { measures }\end{array}$ & http://stacks.cdc.gov/view/cdc/23108 \\
\hline PrEPline & $\begin{array}{l}\text { Clinical Consultation } \\
\text { Center at the University } \\
\text { of California-San } \\
\text { Francisco }\end{array}$ & $\begin{array}{l}\text { PrEP support hotline for } \\
\text { clinicians available } \\
\text { Monday through } \\
\text { Friday from 11:00 am } \\
\text { to 6:00 pm EST }\end{array}$ & $\begin{array}{l}\text { http://nccc.ucsf.edu/clinician-consultation/prep- } \\
\text { pre-exposure-prophylaxis1-855-448-77371- } \\
\text { 855-HIV-PREP }\end{array}$ \\
\hline $\begin{array}{l}\text { Truvada checklist for } \\
\text { prescribers }\end{array}$ & Gilead & $\begin{array}{l}\text { Checklist for providers } \\
\text { before prescribing } \\
\text { PrEP }\end{array}$ & $\begin{array}{l}\text { http://start.truvada.com/hcp/truvadaprep- } \\
\text { checklist }\end{array}$ \\
\hline $\begin{array}{l}\text { Guidance for the Use } \\
\text { of Pre-Exposure } \\
\text { Prophylaxis (PrEP) } \\
\text { to Prevent HIV } \\
\text { Transmission }\end{array}$ & $\begin{array}{l}\text { New York State } \\
\text { Department of Health } \\
\text { AIDS Institute }\end{array}$ & $\begin{array}{l}\text { Checklists for clinicians } \\
\text { to use before and } \\
\text { during PrEP } \\
\text { prescription to guide } \\
\text { laboratory testing and } \\
\text { patient counseling }\end{array}$ & $\begin{array}{l}\text { http://www.hivguidelines.org/clinical-guidelines/ } \\
\text { pre-exposure-prophylaxis/guidance-for-the- } \\
\text { use-of-pre-exposure-prophylaxis-prep-to- } \\
\text { prevent-hiv-transmission/ }\end{array}$ \\
\hline $\begin{array}{l}\text { PrEP and PEP } \\
\text { pocket card }\end{array}$ & $\begin{array}{l}\text { Florida/Caribbean AIDS } \\
\text { Education and Training } \\
\text { Center }\end{array}$ & $\begin{array}{l}\text { Pocket card that } \\
\text { summarizes important } \\
\text { points about the use of } \\
\text { PrEP, along with } \\
\text { protocols for post- } \\
\text { exposure prophylaxis } \\
\text { for HIV, hepatitis A, } \\
\text { and hepatitis B }\end{array}$ & $\begin{array}{l}\text { http://www.fcaetc.org/files/Pocket_Guides/ } \\
\text { PrEPPEP.pdf }\end{array}$ \\
\hline
\end{tabular}

MSM, men who have sex with men; PEP, postexposure prophylaxis; PrEP, preexposure prophylaxis.

favorably with other interventions that are considered to be cost-effective, but could result in PrEP expenditures exceeding \$4 billion annually. ${ }^{47}$ That study found that the cost per quality-adjusted life year is more than US\$100,000 when PrEP is offered to all MSM. The cost per quality-adjusted life year falls below US\$50,000 when PrEP is limited to high-risk MSM, but it increases if PrEP uptake becomes more widespread within this population. These cost-benefit analyses are likely to change when generic formulations of TDF/FTC become available.

The inappropriate use of $\operatorname{PrEP}$ (eg, in a patient who is already HIV positive or is nonadherent, resulting in new HIV seroconversion) is problematic for the patient and his or her loved ones, as well as for the greater community if antiviral-resistant strains of HIV occur. ${ }^{6}$ PrEP may divert resources away from the treatment of $\mathrm{HIV}$-infected patients, especially in settings that already have few resources. $^{35,37,39,51,53,54}$ PrEP may exacerbate health inequities if uptake occurs disproportionately among those with greater health literacy and access to care, or siphons resources away from underin- sured persons who are already infected with HIV and on wait-lists for treatment. ${ }^{39}$ These health inequities could be more severe in low-resource countries.

PrEP has both proponents and detractors among lay members of the populations for whom it has the greatest potential benefit. Larry Kramer, an HIV-positive activist, playwright, and cofounder of Gay Men's Health Crisis, is a notable critic who has accused Truvada users of having "rocks in their heads" and being "cowardly." "55 In a recent article in New York Magazine, some New York City MSM expressed concern based on anecdotes from their social networks that PrEP would encourage men to engage in high-risk sexual activity. Others worried that widespread use of PrEP would harm the popular image of gay men, similar to women in the 1960s who worried that their generation would be branded as promiscuous for adopting oral contraception. Finally, to some gay men PrEP seems like a betrayal of the lessons learned by previous generations ravaged by AIDS: the importance of condoms and sexual prudence. ${ }^{56}$ 
To other gay men, PrEP promises to finally free sex from stigma and paranoia. ${ }^{56}$ Some writers have heralded the dawn of an "HIV sexual revolution" thanks to PrEP, which they argue promises to succeed where the traditional ABCs of HIV prevention-abstinence, being faithful, and condomshave failed. ${ }^{57}$ These men are grateful for the peace of mind they derive from the additional protection against HIV that PrEP provides. As Andrew Sullivan, a well-known HIV-positive gay blogger, writes: "It seems to me simply prudent to have as many weapons in our arsenal against HIV as possible. That means condoms and Truvada. . . . Fight Back. Fight AIDS. Back Truvada." 58

\section{Conclusion}

PrEP with daily oral TDF /FTC reduces the risk of HIV infection among high-risk MSM and transgender women who have sex with men, IDUs, and high-risk heterosexual men and possibly women. As the reduction in HIV incidence plateaus, and with a lack of better office-based strategies for preventing HIV transmission, it is important that all primary care clinicians be aware of PrEP and consider ways to safely implement this effective strategy for reducing HIV risk.

Discussion regarding the cost-effectiveness and opportunity costs will continue, and researchers will explore different delivery methods and dosing. In the meantime, there is widespread consensus that many more people could benefit from PrEP than are currently taking it. Primary care providers are at the front line of PrEP implementation and should embrace this opportunity to increase awareness of PrEP and to prevent HIV infection among those at risk.

The authors thank Mindy Smith, MD, MS, for her assistance with manuscript preparation.

\section{References}

1. Centers for Disease Control and Prevention. Diagnoses of HIV infection in the United States and dependent areas, 2013. HIV surveillance report, vol. 25. Last updated February 23, 2015. Available from: http://www.cdc.gov/hiv/library/reports/surveillance/ 2013/surveillance_Report_vol_25.html/. Accessed November 23, 2015.

2. Chang LW, Serwadda D, Quinn TC, Wawer MJ, Gray RH, Reynolds SJ. Combination implementation for HIV prevention: moving from clinical trial evidence to population-level effects. Lancet Infect Dis 2013;13:65-76.

3. O'Connor EA, Lin JS, Burda BU, Henderson JT, Walsh ES, Whitlock EP. Behavioral sexual risk-reduction counseling in primary care to prevent sexually transmitted infections: a systematic review for the U.S. Preventive Services Task Force. Ann Intern Med 2014;161:874-83.

4. Sherin K, Klekamp BG, Beal J, Martin N. What is new in HIV infection? Am Fam Physician 2014;89: 265-72.

5. Vermund SH, Tique JA, Cassell HM, Pask ME, Ciampa PJ, Audet CM. Translation of biomedical prevention strategies for HIV: prospects and pitfalls. J Acquir Immune Defic Syndr 2013;63(Suppl 1): S12-25.

6. US Public Health Service. Preexposure prophylaxis for the prevention of HIV infection in the United States - 2014. A clinical practice guideline. Atlanta: Centers for Disease Control and Prevention. Available from: http://www.cdc.gov/hiv/pdf/guidelines/ PrEPguidelines2014.pdf\#sthash.g41Z3uzp.dpuf/. Accessed January 16, 2015.

7. Grant RM, Lama JR, Anderson PL, et al. Preexposure chemoprophylaxis for HIV prevention in men who have sex with men. N Engl J Med 2010;363: 2587-99.

8. Baeten JM, Donnell D, Ndase P, et al. Antiretroviral prophylaxis for HIV prevention in heterosexual men and women. N Engl J Med 2012;367:399-410.

9. Thigpen MC, Kebaabetswe PM, Paxton LA, et al. Antiretroviral preexposure prophylaxis for heterosexual HIV transmission in Botswana. N Engl J Med 2012;367:423-34.

10. Choopanya K, Martin M, Suntharasamai P, et al. Antiretroviral prophylaxis for HIV infection in injecting drug users in Bangkok, Thailand (the Bangkok Tenofovir Study): a randomised, double-blind, placebo-controlled phase 3 trial. Lancet 2013;381: 2083-90.

11. Grohskopf LA, Chillag KL, Gvetadze R, et al. Randomized trial of clinical safety of daily oral tenofovir disoproxil fumarate among HIV-uninfected men who have sex with men in the United States. J Acquir Immune Defic Syndr 2013;64:79-86.

12. Okwundu CI, Uthman OA, Okoromah CA. Antiretroviral pre-exposure prophylaxis (PrEP) for preventing HIV in high-risk individuals. Cochrane Database Syst Rev 2012;7:CD007189.

13. International AIDS Society Conference 2015. The Vancouver consensus. Available from: http:// vancouverconsensus.org/. Accessed September 8, 2015.

14. Mimiaga MJ, White JM, Krakower DS, Biello KB, Mayer KH. Suboptimal awareness and comprehension of published preexposure prophylaxis efficacy results among physicians in Massachusetts. AIDS Care 2014;26:684-93. 
15. Karris MY, Beekmann SE, Mehta SR, Anderson $\mathrm{CM}$, Polgreen PM. Are we prepped for preexposure prophylaxis (PrEP)? Provider opinions on the realworld use of PrEP in the United States and Canada. Clin Infect Dis 2014;58:704-12.

16. Flash C, Landovitz R, Giler RM, et al. Two years of Truvada for pre-exposure prophylaxis utilization in the US. J Int AIDS Soc 2014;17(4 Suppl 3):19730.

17. Krakower D, Mayer KH. What primary care providers need to know about preexposure prophylaxis for HIV prevention: a narrative review. Ann Intern Med 2012;157:490-7.

18. McCormack S, Dunn D. Pragmatic open-label randomised trial of preexposure prophylaxis in MSM: the PROUD study. Paper presented at: Conference on Retroviruses and Opportunistic Infections, Seattle, WA (February 23-26, 2015). Available from: http://www.croiconference.org/sessions/pragmaticopen-label-randomised-trial-preexposure-prophylaxisproud-study. Accessed September 3, 2015.

19. Liu A, Cohen S, Vittinghoff E, et al. Adherence, sexual behavior and HIV/STI incidence among men who have sex with men (MSM) and transgender women (TGW) in the US PrEP demonstration (Demo) project. Abstract TUAC0202. Paper presented at: 8th International AIDS Society Conference on HIV Pathogenesis, Treatment, and Prevention, Vancouver (July 19-22, 2015).

20. Peterson L, Taylor D, Roddy R, et al. Tenofovir disoproxil fumarate for prevention of HIV infection in women: a phase 2, double-blind, randomized, placebo-controlled trial. PLoS Clin Trials 2007;2(5): e27.

21. Van Damme L, Corneli A, Ahmed K, et al. Preexposure prophylaxis for HIV infection among African women. N Engl J Med 2012;367:411-22.

22. Marrazzo JM, Ramjee G, Richardson BA, et al. Tenofovir-based preexposure prophylaxis for HIV infection among African women. N Engl J Med 2015;372:509-18.

23. Abdool Karim Q, Abdool Karim SS, Frohlich JA, et al. Effectiveness and safety of tenofovir gel, an antiretroviral microbicide, for the prevention of $\mathrm{HIV}$ infection in women. Science 2010;329:1168-74.

24. Baeten JD, Heffron R, Kidoguchi L, et al. Near elimination of HIV transmission in the Partners Demonstration Project of PrEP and ART in Uganda and Kenya. Paper presented at: Conference on Retroviruses and Opportunistic Infections, Seattle, WA (February 23-26, 2015). Available from: http:// www.croiconference.org/sessions/near-eliminationhiv-transmission-demonstration-project-prep-and-art. Accessed September 3, 2015.

25. Eunice Kennedy Shriver National Institute of Child Health and Human Development, National Institute on Drug Abuse, National Institute of Mental Health. Pre-exposure prophylaxis in YMSM. Bethesda (MD): National Library of Med- icine. Available from: https://clinicaltrials.gov/ct2/ show/NCT01033942. Accessed November 23, 2015.

26. Eunice Kennedy Shriver National Institute of Child Health and Human Development. An open label demonstration project and phase II safety study of pre-exposure prophylaxis use among 15 to 17 year old young men who have sex with men (YMSM). Bethesda (MD): National Library of Medicine. Available from: https://clinicaltrials.gov/ct2/show/ NCT01769456. Accessed November 23, 2015.

27. National Institute of Allergy and Infectious Diseases. Evaluating the acceptability, safety, and use of daily truvada pre-exposure prophylaxis in healthy, HIVuninfected adolescents. Bethesda (MD): National Library of Medicine. Available from: https:// clinicaltrials.gov/ct2/show/NCT02213328. Accessed November 23, 2015.

28. Eunice Kennedy Shriver National Institute of Child Health and Human Development. An open label demonstration project and phase II safety study of pre-exposure prophylaxis. Bethesda (MD): National Library of Medicine. Available from: https:// clinicaltrials.gov/ct2/show/NCT01769456. Accessed November 23, 2015.

29. National Institute of Allergy and Infectious Diseases. The ADAPT study: use of emtricitabine and tenofovir disoproxil fumarate for pre-exposure prophylaxis (PrEP). In: Bethesda (MD): National Library of Medicine. Available from: https://clinicaltrials.gov/ ct2/show/NCT01327651. Accessed November 23, 2015.

30. French National Institute for Health and Medical Research-French National Agency for Research on AIDS and Viral Hepatitis. On demand antiretroviral pre-exposure prophylaxis for HIV infection in men who have sex with men. Bethesda (MD): National Library of Medicine. Available from: https:// clinicaltrials.gov/ct2/show/NCT01473472. Accessed November 23, 2015.

31. Bill and Melinda Gates Foundation, National Institute of Allergy and Infectious Diseases, National Institutes of Health. Phase II safety and acceptability of an investigational injectable product, TMC278LA, for pre-exposure prophylaxis. Bethesda (MD): National Library of Medicine. Available from: https://clinicaltrials.gov/ ct2/show/NCT02165202. Accessed November 23, 2015.

32. ViiV Healthcare, GlaxoSmithKline. Study to evaluate the safety tolerability and acceptability of long acting injections of the human immunodeficiency virus (HIV) integrase inhibitor, GSK1265744, in HIV uninfected men (ECLAIR). Bethesda (MD): National Library of Medicine. Available from: https://clinicaltrials.gov/ct2/show/NCT02076178. Accessed November 23, 2015.

33. Molina J-M, Capitant C, Spire B, et al. On demand PrEP with oral TDF-FTC in MSM: results of the ANRS Ipergay trial. Abstract presented at: Conference on Retroviruses and Opportunistic Infections, 
Seattle, WA (February 23-26, 2015). Available from: http://www.croiconference.org/sessions/demandprep-oral-tdf-ftc-msm-results-anrs-ipergay-trial. Accessed September 3, 2015.

34. ACOG Committee opinion no 595: Committee on Gynecologic Practice: preexposure prophylaxis for the prevention of human immunodeficiency virus. Obstet Gynecol. 2014;123:1133-6.

35. Baeten JM, Grant R. Use of antiretrovirals for HIV prevention: what do we know and what don't we know? Curr HIV/AIDS Rep 2013;10:142-51.

36. Cohen MS, Baden LR. Preexposure prophylaxis for HIV-where do we go from here? N Engl J Med 2012;367:459-61.

37. Abdool Karim SS, Gray GE, Martinson N. Clinical decisions. Preexposure prophylaxis for HIV prevention. N Engl J Med 2012;367:462-5.

38. Marcus JL, Buisker T, Horvath T, et al. Helping our patients take HIV pre-exposure prophylaxis (PrEP): a systematic review of adherence interventions. HIV Med 2014;15:385-95.

39. Plosker GL. Emtricitabine/tenofovir disoproxil fumarate: a review of its use in $\mathrm{HIV}-1$ pre-exposure prophylaxis. Drugs 2013;73:279-91.

40. New York State Department of Health AIDS Institute. Guidance for the use of pre-exposure prophylaxis (PrEP) to prevent HIV transmission. October 2015. Available from: http://www.hivguidelines.org/ wp-content/uploads/2015/10/PrEP-Guidance_10-1415.pdf. Accessed November 23, 2015.

41. Amico KR, Mansoor LE, Corneli A, Torjesen K, van der Straten A. Adherence support approaches in biomedical HIV prevention trials: experiences, insights and future directions from four multisite prevention trials. AIDS Behav 2013;17:2143-55.

42. Landovitz RJ. PrEP for HIV prevention: What we know and what we still need to know for implementation. Paper presented at: Conference on Retroviruses and Opportunistic Infections, Seattle, WA (February 23-26, 2015). Available from http:// www.croiwebcasts.org/console/player/25535. Accessed July 13, 2015.

43. Kasonde M, Niska RW, Rose C, Henderson FL, Segolodi TM, et al. Bone mineral density changes among HIV-uninfected young adults in a randomised trial of pre-exposure prophylaxis with tenofovir-emtricitabine or placebo in Botswana. PLoS One 2014;9(3):e90111.

44. Liu AY, Vittinghoff E, Sellmeyer DE, et al. Bone mineral density in HIV-negative men participating in a tenofovir pre-exposure prophylaxis randomized clinical trial in San Francisco. PLoS One 2011;6(8): e23688.
45. Solomon MM, Lama JR, Glidden DV, et al. Changes in renal function associated with oral emtricitabine/tenofovir disoproxil fumarate use for HIV pre-exposure prophylaxis. AIDS 2014;28: 851-9.

46. Tripathi A, Whiteside YO, Duffus WA. Perceptions and attitudes about preexposure prophylaxis among seronegative partners and the potential of sexual disinhibition. South Med J 2013;106:558-64.

47. Juusola JL, Brandeau ML, Owens DK, Bendavid E. The cost-effectiveness of preexposure prophylaxis for HIV prevention in the United States in men who have sex with men. Ann Intern Med 2012;156:541-50.

48. AIDS Foundation of Chicago. Truvada track-monitoring insurance and Medicaid coverage of Truvada for PrEP. My PrEP Experience. 2015. Available from: http://myprepexperience.blogspot.com/p/ truvada-track.html. Accessed September 3, 2015.

49. New York City Department of Health and Mental Hygiene. Health department launches new PrEP \& PEP campaign: new ways to prevent HIV. Press release no. 003-15. January 12, 2015. Available from: http://www.nyc.gov/html/doh/html/pr2015/pr00315.shtml. Accessed September 3, 2015.

50. New York City Department of Health and Mental Hygiene. New York City biomedical HIV prevention referral list. Available from: http://www.nyc.gov/ html/doh/downloads/pdf/ah/provider-clinical-sitechecklist.pdf. Accessed September 3, 2015.

51. Jay JS, Gostin LO. Ethical challenges of preexposure prophylaxis for HIV. JAMA 2012;308:867-8.

52. Campbell JD, Herbst JH, Koppenhaver RT, Smith DK. Antiretroviral prophylaxis for sexual and injection drug use acquisition of HIV. Am J Prev Med 2013;44(1 Suppl 2):S63-9.

53. Wood LV. Why I voted "no" to Truvada PrEP. Ann Intern Med 2012;157:519-20.

54. Hurt CB, Eron JJ Jr, Cohen MS. Pre-exposure prophylaxis and antiretroviral resistance: HIV prevention at a cost? Clin Infect Dis 2011;53:1265-70.

55. Healy P. A lion still roars, with gratitude: Larry Kramer lives to see his 'Normal Heart' filmed for TV. New York Times, May 21, 2014.

56. Murphy T. Sex without fear: The new pill that could revolutionize gay life is reawakening old arguments. New York Magazine, July 13, 2014.

57. McNeil D. Are we ready for H.I.V.'s sexual revolution? New York Times, May 23, 2014.

58. Sullivan A. Hey, wait a minute, Mr. Kramer. The Dish [Internet]. May 27, 2014. Available from: http://dish.andrewsullivan.com/2014/05/27/hey-waita-minute-mr-kramer/. Accessed July 13, 2015. 